\title{
A Study of the Application of Residue from Burned Biomass in Mortars
}

\author{
Enori Gemelli*, Arthur Adelino de Freitas Cruz, Nelson Heriberto Almeida Camargo \\ Department of Mechanical Engineering, Center of Technological Sciences, UDESC \\ Santa Catarina State University, Bom Retiro, 89223-100 Joinville - SC, Brazil
}

Received: October 7, 2003; Revised: June 30, 2004

\begin{abstract}
The goal of this work was to study the viability of burnt biomass residue from a pulp and paper plant applied as a raw material for mortar used in the construction industry. The waste bottom ash - was incorporated into the mortar as a mineral addition to the Portland cement. The effect of the waste's grain size on the properties of mortars containing $10 \%$ in volume of waste was investigated, as well as the effect of the concentration of waste with grain size under $0.15 \mathrm{~mm}$. The samples were evaluated after 28 days of aging by uniaxial compression, leaching test and scanning electron microscopy. These characterization techniques indicated that the properties of the mortars depend on the concentration, granulation and size distribution of the waste in the mortar's structure. Furthermore, some chemical elements may be present in stabilized and/or encapsulated form in the cement matrix.
\end{abstract}

Keywords: waste, mortar, construction materials

\section{Introduction}

In the last two decades, the Brazilian NBR 10004 code has forced factories to adopt suitable treatment and disposal procedures for their industrial wastes. Since then, industrial wastes have become a major concern, involving legal environmental responsibility and final disposal costs. In an effort to minimize these costs, many studies have concentrated on assessing the utilization of certain wastes as raw materials in the construction industry ${ }^{1-5}$. Depending upon their chemical composition, these wastes can be incorporated into mortars to partially replace cement and/or aggregate. In a recent study ${ }^{5}$, we investigated the performance of mortars produced with wastes from industrial pulp and paper processes. Four types of residue, namely fibers, dregs, bottom ash and grit, were selected and studied. Bottom ash and dregs were used to partially replace Portland cement, and fiber and grit were used to partially replace aggregate. Our conclusion regarding these wastes, as raw materials for mortars were that bottom ash stands out from the other types of residue as a mineral addition to the Portland cement. Actually, utilization of bottom ash in public constructions is encouraged in other countries ${ }^{6,7}$. Usually, mechanical strength and environmental impact are evaluated on these materials. Mechanical strength is directly related with the defects in mortar microstructure ${ }^{1,2,4,5}$. These defects are broadly evaluated by microscopic analyses, mainly by scan- ning electron microscopy, which provides important data on mortar studies. On the other hand, the major concern regarding the utilization of these materials is the environmental impact they can cause ${ }^{6-10}$. Experiments carried out during three years on road constructions under real conditions ${ }^{7}$, have shown a low contribution of bottom ash on the composition of the percolation water. Nevertheless, the utilization of bottom ash as raw material depends on the regulations of each country. Therefore, this work proposed to make a more in-depth investigation of the effect of bottom ash on the properties of mortars, evaluating the effect of the concentration and size granulation of this residue on the mechanical, microstructural and environmental impact.

\section{Materials and Experimental Procedure}

The materials used in this work were selected based on earlier results from the production of mortars, whose properties were found to depend on the quality of the raw materials. Most of these raw materials, particularly the most widely commercialized ones, have high levels of impurities that strongly influence the characteristics and properties of mortars. Therefore, only high quality Portland cement and a washed aggregate (sand), prepared in the laboratory according to the AFS (American Foundry Society) 106-87-S standard, were used in this study in order to evaluate the

*e-mail: gemelli@joinville.udesc.br 
performance of the mortars without the interference of impurities.

\subsection{CPV ARI portland cement}

The CPV ARI Portland cement, which was supplied by Companhia de Cimento Itambé, has a density of $3,12 \mathrm{~g} / \mathrm{cm}^{3}$ and high strength at early ages - about $27 \mathrm{MPa}$ after one day, i.e. about $50 \%$ of its final strength obtained after 28 days - as well as good resistance to sulphate environments. Table 1 lists the chemical composition of CPV ARI Portland cement. This composition is equivalent to the oxide composition of the basic compounds of Portland cement after calcination, which are mainly $3 \mathrm{CaO} . \mathrm{SiO}_{2}, 2 \mathrm{CaO} . \mathrm{SiO}_{2}$, $3 \mathrm{CaO} \cdot \mathrm{Al}_{2} \mathrm{O}_{3}$ and $4 \mathrm{CaO} \cdot \mathrm{Al}_{2} \mathrm{O}_{3} \cdot \mathrm{Fe}_{2} \mathrm{O}_{3}$.

\subsection{Solid bottom ash waste}

Solid bottom ash is a residue of burnt eucalyptus and pine, which are used to produce thermal energy. This residue, composed of hard agglomerates of 1 to $3 \mathrm{~cm}$, was ground to produce raw material, using water and a porcelain ball mill at $50 \mathrm{rpm}$ for $12 \mathrm{~h}$. The proportion of porcelain balls and waste was 2:1 by mass. After grinding, the sludge was dried for $4 \mathrm{~h}$ in a rotary evaporator at $70{ }^{\circ} \mathrm{C}$ (silicone oil temperature) at $8 \mathrm{rpm}$. Table 2 lists the characteristics of solid bottom ash waste.

The powder thus obtained was sieved through the following mesh sizes, according to the NBR 7217 code: 20, $30,40,50,70,100,140,200$ and 270-mesh. The operation was performed in a mechanical shaker for 15 min, using $50 \mathrm{~g}$ of residue. The mass retained on each sieve was determined by mass difference. Table 3 indicates the granulometric distribution of the residue used in this study.

Table 3 indicates that $72.74 \%$ of the residue sifted through the 270-mesh sieve had a grain size of up to $0.053 \mathrm{~mm}$ and that $91.06 \%$ of the residue sifted through the 100 -mesh sieve had a grain size of up to $0.150 \mathrm{~mm}$, confirming that the residue's grain size was small after $12 \mathrm{~h}$ of grinding.

\subsection{Aggregate}

The aggregate used in this work originated from sedimentary layers formed in riverbeds near Joinville, state of Santa Catarina, Brazil, and was supplied by Mineração Veiga Ltda of Araquari, SC. This aggregate had a real density of about $1.5 \mathrm{~g} / \mathrm{cm}^{3}$ and presented an AFS size module of 88.88 and $0.2 \%$ of clay. The granulometric distribution of the aggregate (sand) is presented in Table 4.

\subsection{Production of mortars}

The bottom ash was incorporated into the mortars as a mineral addition to the Portland cement. The samples were prepared in two steps. In the first, samples were prepared containing $90 \%$ of cement plus $10 \%$ by volume of bottom ash. This mixture was used with different bottom ash granulations to study the effect of the residue's grain size on the mortar's properties. Five different grain sizes were used: between 1 and $2 \mathrm{~mm}$, between 0.57 and $1 \mathrm{~mm}$, be-

Table 1. Chemical composition of CPV ARI Portland cement (CIA de Cimento Itambé).

\begin{tabular}{cc}
\hline Compound & Mass (\%) \\
\hline $\mathrm{SO}_{3}$ & 2.98 \\
Free $\mathrm{CaO}$ & 1.59 \\
$\mathrm{MgO}$ & 2.91 \\
$\mathrm{Al}_{2} \mathrm{O}_{3}$ & 4.44 \\
$\mathrm{SiO}_{2}$ & 19.49 \\
$\mathrm{Fe}_{2}$ & 2.86 \\
$\mathrm{CaO}_{3}$ & 62.52 \\
$\mathrm{Na}_{2} \mathrm{O}$ and $\mathrm{K}_{2} \mathrm{O}$ & 0.56 \\
Residue & 0.66 \\
\hline
\end{tabular}

Table 2. Characteristics of solid bottom ash waste.

\begin{tabular}{cc}
\hline Humidity $\left(\mathrm{H}_{2} \mathrm{O}\right)$ & $7.0 \%$ (by mass) \\
\hline $\mathrm{pH}$ & 10.21 \\
Real density & $2.70 \mathrm{~g} / \mathrm{cm}^{3}$ \\
$\mathrm{C}$ & $4.0 \%$ \\
$\mathrm{P}$ & $4270.0 \mathrm{ppm}$ \\
$\mathrm{SiO}_{2}$ & $1.66 \%$ \\
$\mathrm{~N}$ & $800.0 \mathrm{mg} / \mathrm{l}$ \\
$\mathrm{K}$ & $29870.0 \mathrm{ppm}$ \\
$\mathrm{Na}$ & $46000.0 \mathrm{ppm}$ \\
$\mathrm{S}$ & $2.4 \mathrm{mg} / \mathrm{l}$ \\
$\mathrm{CaO}$ & $36.4 \%$ \\
$\mathrm{MgO}$ & $1.43 \%$ \\
Inert ash & $47.54 \%$ \\
\hline
\end{tabular}

Table 3. Granulometric distribution of the bottom ash waste after grinding in agreement with NBR 77211 code.

\begin{tabular}{|c|c|c|c|}
\hline \multirow[t]{2}{*}{ Sieve mesh } & \multirow[t]{2}{*}{$\begin{array}{l}\text { Sieve mesh } \\
\text { size }(\mathrm{mm})\end{array}$} & \multicolumn{2}{|c|}{$\begin{array}{l}\text { Mass retained } \\
\text { on the sieve }(\%)\end{array}$} \\
\hline & & $\begin{array}{l}\text { Amount } \\
\text { per sieve }\end{array}$ & $\begin{array}{c}\text { Total } \\
\text { amount }\end{array}$ \\
\hline 20 & 0.850 & 0.98 & 0.98 \\
\hline 30 & 0.590 & 1.54 & 2.52 \\
\hline 40 & 0.420 & 1.32 & 3.84 \\
\hline 50 & 0.290 & 1.58 & 5.42 \\
\hline 70 & 0.240 & 2.00 & 7.42 \\
\hline 100 & 0.150 & 1.52 & 8.94 \\
\hline 140 & 0.106 & 2.40 & 11.34 \\
\hline 200 & 0.075 & 7.20 & 18.54 \\
\hline 270 & 0.053 & 8.72 & 27.26 \\
\hline \multicolumn{2}{|c|}{ Bottom dish } & 72.74 & 100.00 \\
\hline
\end{tabular}


tween 0.30 and $0.57 \mathrm{~mm}$, between 0.15 and $0.30 \mathrm{~mm}$ and under $0.15 \mathrm{~mm}$. The second step consisted of studying the effect of the concentration of residue having a grain size of less than $0.15 \mathrm{~mm}$. Samples were prepared with cement plus $5,10,15$ and $20 \%$ by volume of waste. The raw materials used to produce the mortars were oven-dried and then mixed in a mass proportion of three parts of sand (aggregate) for one of cement plus bottom ash. The mortars were produced according to the Brazilian NBR 12821 code. Table 5 lists the mixtures used in the preparation of the mortars. The samples were casted in three mortar layers into $50 \mathrm{~mm}$ diameter and $100 \mathrm{~mm}$ long molds. Each layer was compacted using 20 strokes of a standard rod. The samples were removed from the molds after $24 \mathrm{~h}$ and then they were cured in alkaline water for 28 days. For each formulation was produced 10 samples. Upon completion of the curing process, the samples were subjected to mechanical axial compression tests. The samples were coated with sulfur to render them flat and smooth surfaces for better contact with the mechanical compression devices. The microstructural characterization, performed by scanning electron microscopy (SEM), were carried on the samples fragments, obtained from the mechanical test. Before the observation, the fragments were dried in a drying-room during $24 \mathrm{~h}$ at $100{ }^{\circ} \mathrm{C}$. The fragments were fasten on a sample rack with carbon glue and metallized with a $12 \mathrm{~nm}$ gold layer.

\section{Experimental Results}

3.1. Axial compression strength of the samples containing $10 \%$ of bottom ash with different grain sizes

Table 4. Granulometric distribution of the aggregate in agreement with NBR 77211 code.

\begin{tabular}{|c|c|c|c|}
\hline \multirow[t]{2}{*}{ Sieve mesh } & \multirow[t]{2}{*}{$\begin{array}{l}\text { Sieve mesh } \\
\text { size }(\mathrm{mm})\end{array}$} & \multicolumn{2}{|c|}{$\begin{array}{l}\text { Mass retained } \\
\text { on the sieve }(\%)\end{array}$} \\
\hline & & $\begin{array}{l}\text { Amount } \\
\text { per sieve }\end{array}$ & $\begin{array}{c}\text { Total } \\
\text { amount }\end{array}$ \\
\hline 10 & 2.000 & 0.05 & 0.05 \\
\hline 20 & 0.850 & 0.17 & 0.22 \\
\hline 30 & 0.590 & 8.58 & 8.80 \\
\hline 40 & 0.420 & 29.84 & 38.64 \\
\hline 50 & 0.290 & 61.36 & 100.00 \\
\hline
\end{tabular}

The test was performed at a speed of $1 \mathrm{~mm} / \mathrm{min}$ in a mechanical testing machine. Figure 1 illustrates the average rupture stress of the mortars.

It can be seen in Fig. 1, the mechanical strength of the mortar tended to decrease as the residue's grain size increased. The residue caused a slight decrease of approximately $8.5 \%$ in the mechanical strength of the samples with waste grain sizes of up to $0.15 \mathrm{~mm}$. A significant drop in the average mechanical strength was observed when residue grain sizes of 0.15 to $0.30 \mathrm{~mm}$ were used. Afterward, the mechanical strength tends to decline slowly and steady as the grain sizes increase.

\subsection{Axial compression strength of samples with grain size up to $0.15 \mathrm{~mm}$ in different concentrations}

The effect of the concentration of residue with a grain size of up to $0.15 \mathrm{~mm}$ incorporated into the mortars is presented in Fig. 2. The mechanical strength decreased slightly and linearly with increasing amounts of residue, corresponding to a reduction of about $3.85 \%$ for each addition of $5 \%$ of bottom ash. These results led to the conclusion that it is more advantageous to produce mortars containing $20 \%$ of residue with grain sizes of up to $0.15 \mathrm{~mm}$ than with $10 \%$ of residue with grain sizes above $0.15 \mathrm{~mm}$.

\subsection{Microstructural and morphological analyses of raw materials}

Bottom ash waste. The bottom ash powder was found to have a variety of particle shapes and sizes, as illustrated in Fig. 3. Calcium, silicium, aluminum and potassium were detected through chemical analyses performed by energy dispersive spectroscopy (EDS) (see Fig. 4). These analyses showed that the residue was composed mainly of silicium and calcium-containing compounds. The high amount of silicium indicated that the inert bottom ash listed in Table 2 consisted essentially of silica.

Aggregate. SEM observations of the aggregate to assess its quality revealed that it contained a very small amount of impurities, according to the supplier's specifications (Fig. 5). This finding is corroborated in Fig. 6, which shows the EDS analyses, indicating a very small amount of aluminum and confirming that the aggregate consisted basically of silica and traces of clay. Figure 5 also shows that

Table 5. Amount of materials used to produce 10 samples for each formulation.

\begin{tabular}{ccccc}
\hline Bottom ash $(\%$ by volume $)$ & Aggregate $(\mathrm{g})$ & Cement $(\mathrm{g})$ & Bottom ash $(\mathrm{g})$ & Water/cement ratio \\
\hline 0.0 & 3744 & 1248.0 & 0 & 0.48 \\
5.0 & 3744 & 1185.6 & 54 & 0.48 \\
10.0 & 3744 & 1123.2 & 108 & 0.49 \\
15.0 & 3744 & 1060.8 & 162 & 0.49 \\
20.0 & 3744 & 998.4 & 216 & 0.49 \\
\hline
\end{tabular}




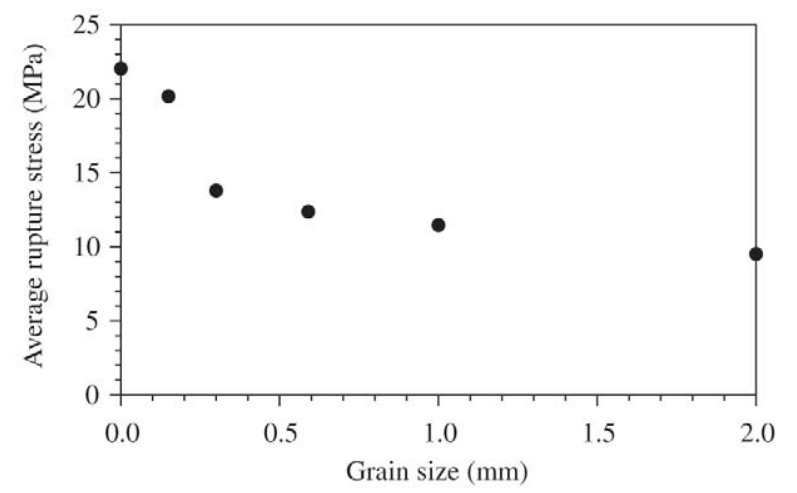

Figure 1. Effect of residue grain size on the mortars' axial mechanical strength.

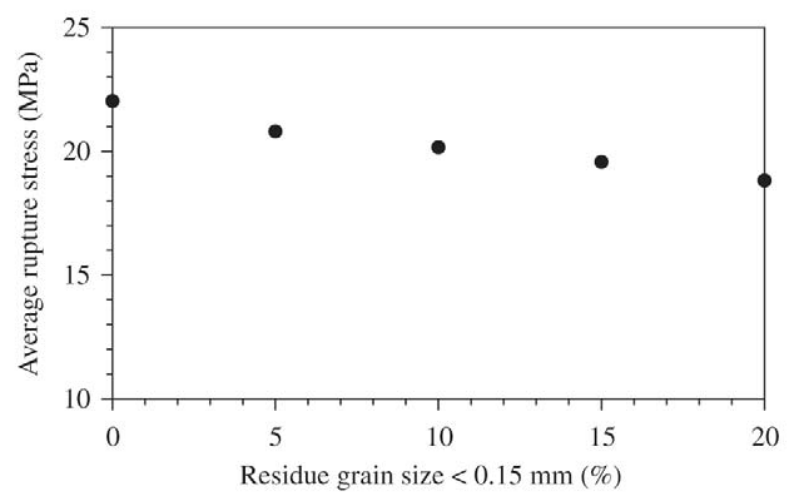

Figure 2. Effect of the concentration of waste with grain sizes of less than $0.15 \mathrm{~mm}$ on the mortars' axial mechanical strength.

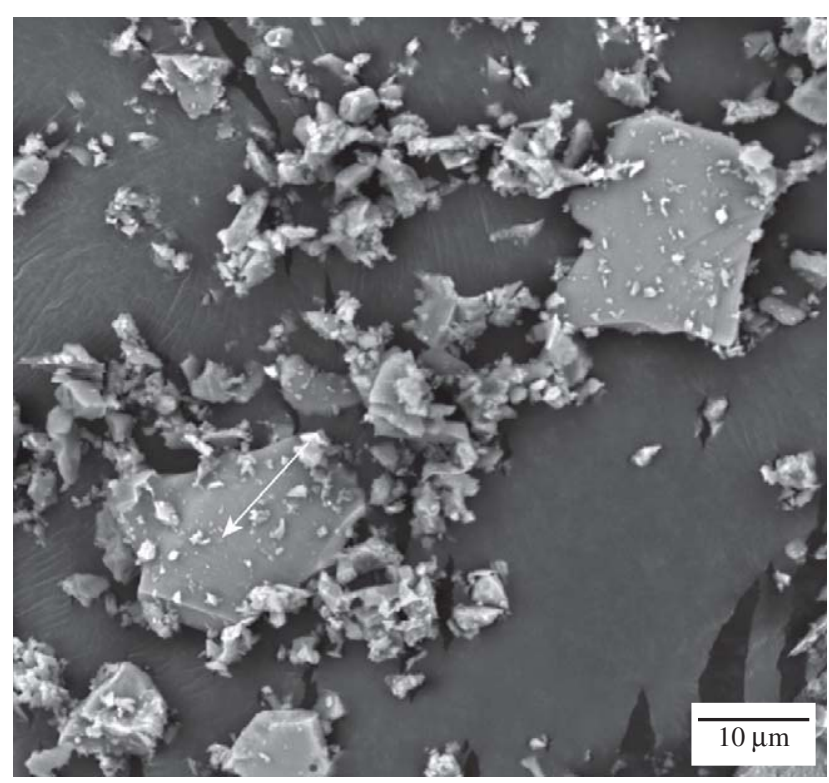

Figure 3. SEM micrograph showing a variety of particle shapes and sizes. The arrow on this figure shows the place where EDS spectrum was performed.

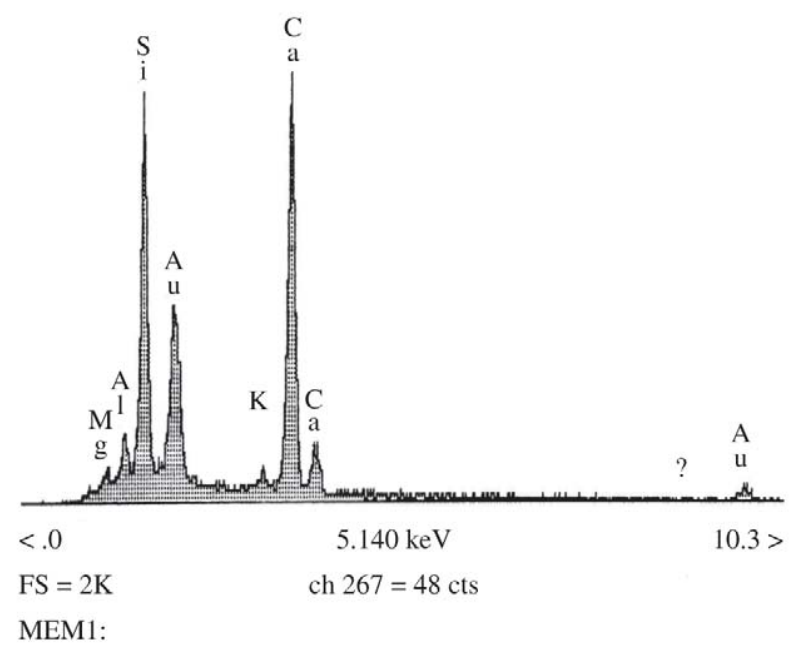

Figure 4. EDS spectrum showing the residue's main chemical elements. The gold $(\mathrm{Au})$ on the spectrum is coming from the preparation of the sample (metallization).

the average grain size of 0.11 to $0.15 \mathrm{~mm}$ met the specifications of the AFS 80 to 90 standards for aggregates.

CPV ARI cement. This cement presented different particle shapes and sizes (Fig. 7) similar to those of bottom ash. Silica and calcium crystals, as well as spherical-shaped pozzolan, are clearly visible in Fig. 7. As illustrated in Fig. 8, the chemical composition of cement particles consists of $\mathrm{Ca}, \mathrm{Si}, \mathrm{Al}$ and $\mathrm{Mg}$, which are the main chemical elements in cement compounds.

\subsection{Microstructural and morphological characterization of mortars}

Mortar without bottom ash. The samples were characterized on the fracture cross-section, where good adherence of the gel (cement paste) on the aggregate (Fig. 9) and low porosity was observed. Figure 10 illustrates the good nucleation and growth of ettringite, revealing a normal hydration process during the 28-day curing period. The ettringite crystals are also known as anhydrite crystals and are formed by precipitation of aqueous ions of aluminum, sulfur, and calcium, known as hydrated calcium aluminum sulfate hydroxide.

Mortar with $10 \%$ of bottom ash and different grain sizes. Mortars with grain sizes of 1 to $2 \mathrm{~mm}$ and 0.59 to $1 \mathrm{~mm}$ displayed sites containing larger concentrations of bottom ash, as indicated in Figs. 11 to 14 . These figures show that bottom ash grains disintegrate readily in mortar during its manufacturing process or when the material is subjected to compressive forces. This is possible because the residue grain is formed by an agglomerate of its particles. Furthermore, sites containing high concentrations of residue impede the nucleation of ettringite. 


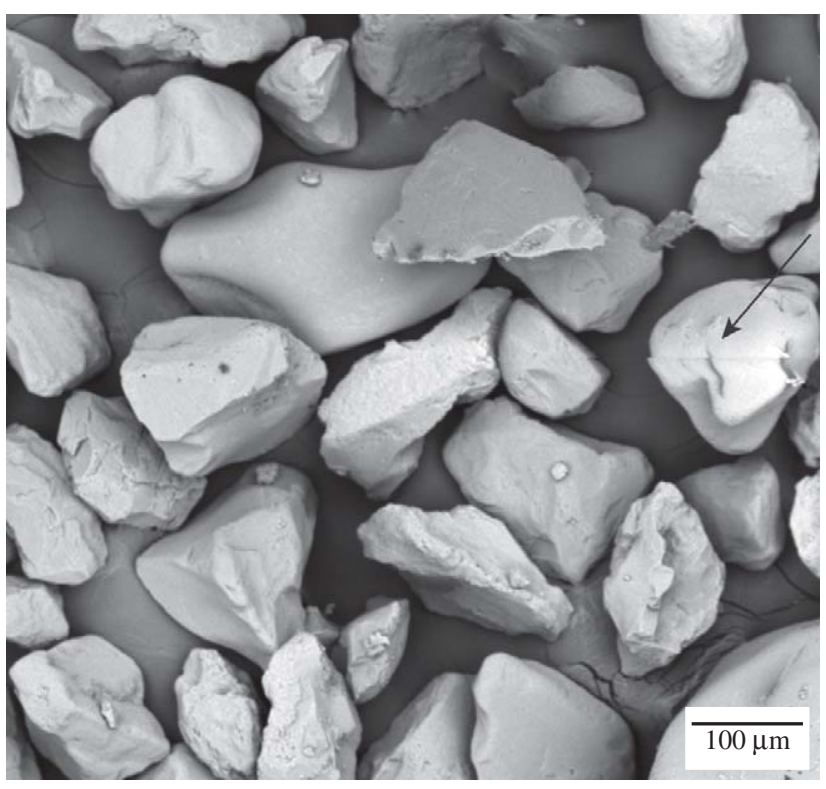

Figure 5. SEM micrograph of the aggregate's morphology. The arrow on this figure shows the place where EDS spectrum was performed.

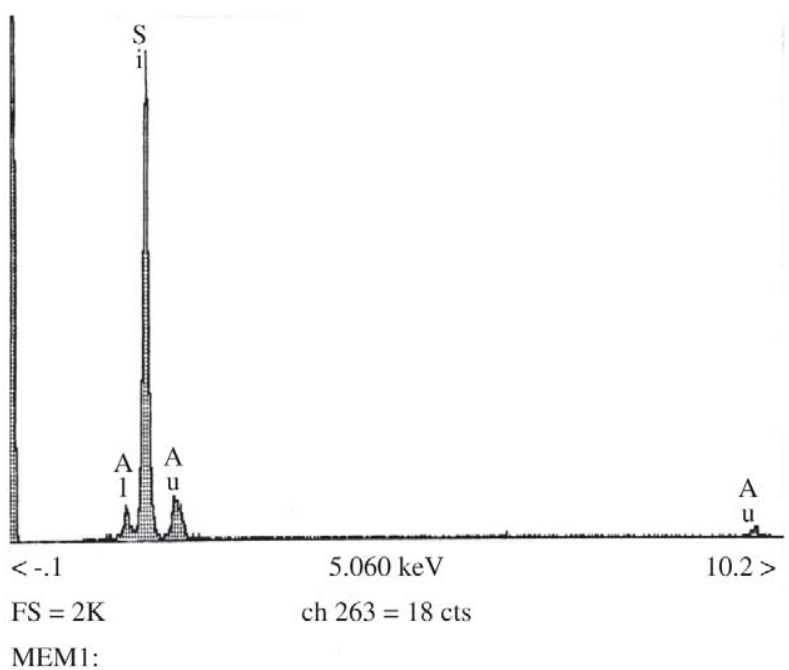

Figure 6. EDS analysis showing traces of clay in the aggregate. The gold $(\mathrm{Au})$ on the spectrum is coming from the preparation of the sample (metallization).

As illustrated in Figs. 15, 16, 17 and 18, the grain sizes of 0.30 to $0.59 \mathrm{~mm}$ and 0.15 to $0.30 \mathrm{~mm}$ displayed better homogenization of the bottom ash in the mortar than did the grain sizes of 1 to $2 \mathrm{~mm}$ and 0.59 to $1 \mathrm{~mm}$. Ettringite crystals were found to germinate and grow in preferential regions, as indicated in Fig. 16, possibly due to larger

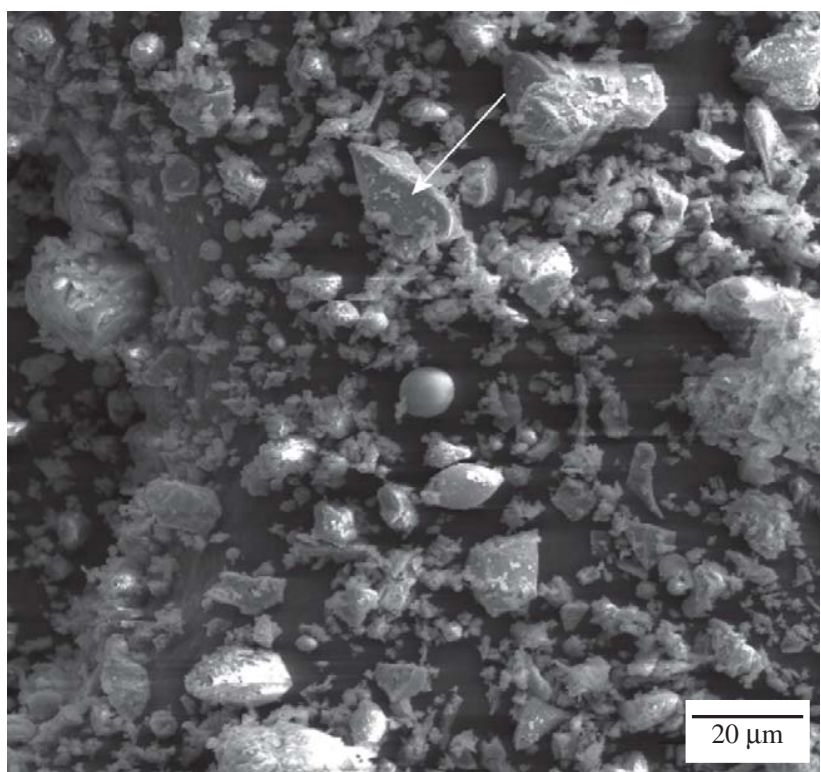

Figure 7. SEM micrograph showing varied cement particle sizes as received (unreacted cement). The arrow on this figure shows the place where EDS spectrum was performed.

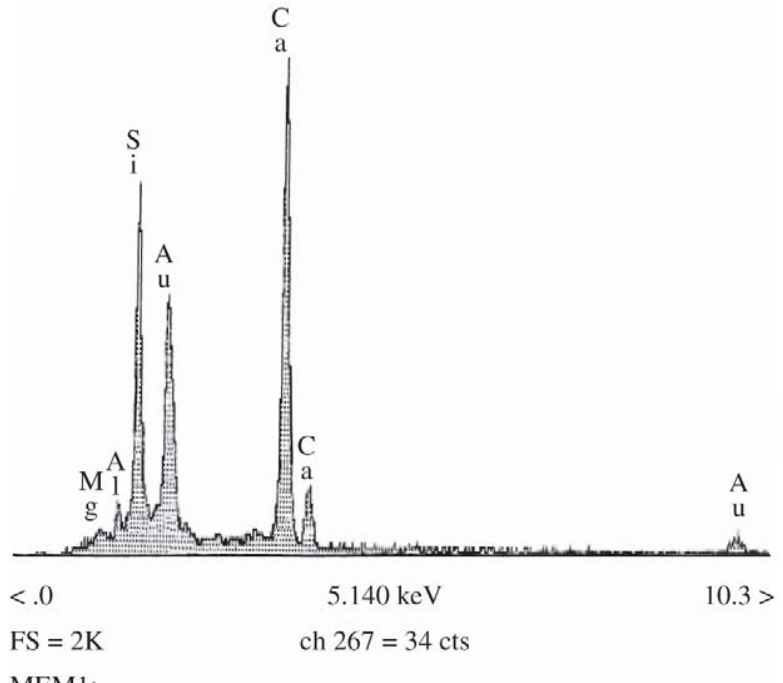

Figure 8. EDS image of the main chemical composition of the cement. The gold $\mathrm{(Au}$ ) on the spectrum is coming from the preparation of the sample (metallization).

amounts of water dissolved in these regions of the mortar (better conditions of hydration) and/or larger concentrations of calcium oxide.

Figures 19 and 20 depict test specimens containing bottom ash with a grain size of under $0.15 \mathrm{~mm}$. This grain size promoted a better formation of ettringite crystals than the 


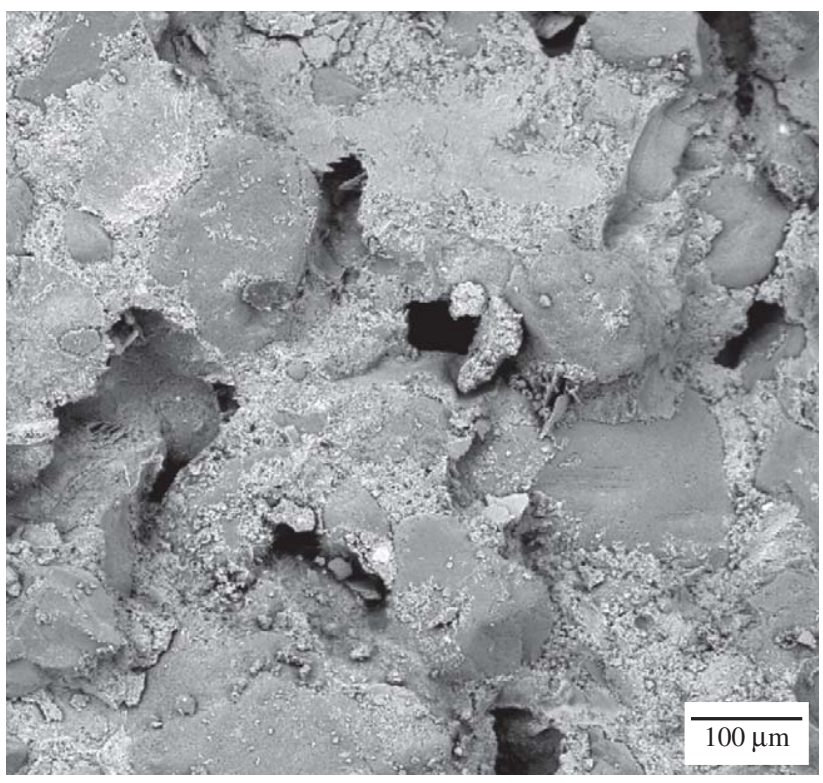

Figure 9. SEM micrograph of the mortar's gel/aggregate interface without residue.

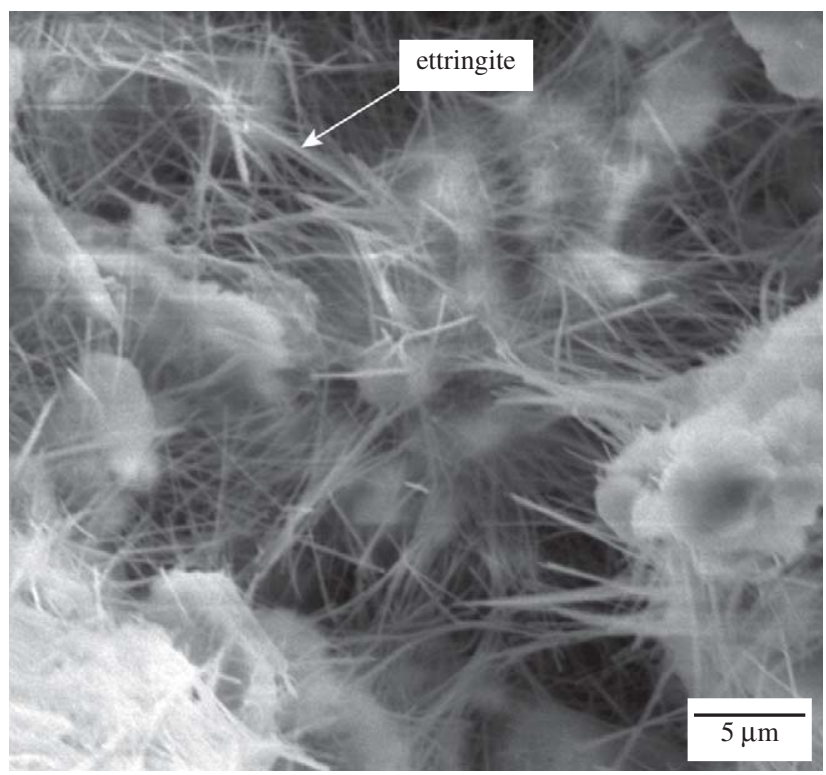

Figure 10. SEM micrograph of ettringite crystals in the mortar without residue.

other grain sizes studied. Among the samples containing residue, this grain size offered the more homogeneous gel/aggregate interface.

Mortars containing different concentrations of residue with grain sizes under $0.15 \mathrm{~mm}$. The mortar containing $5 \%$ of residue displayed a good gel/aggregate interface

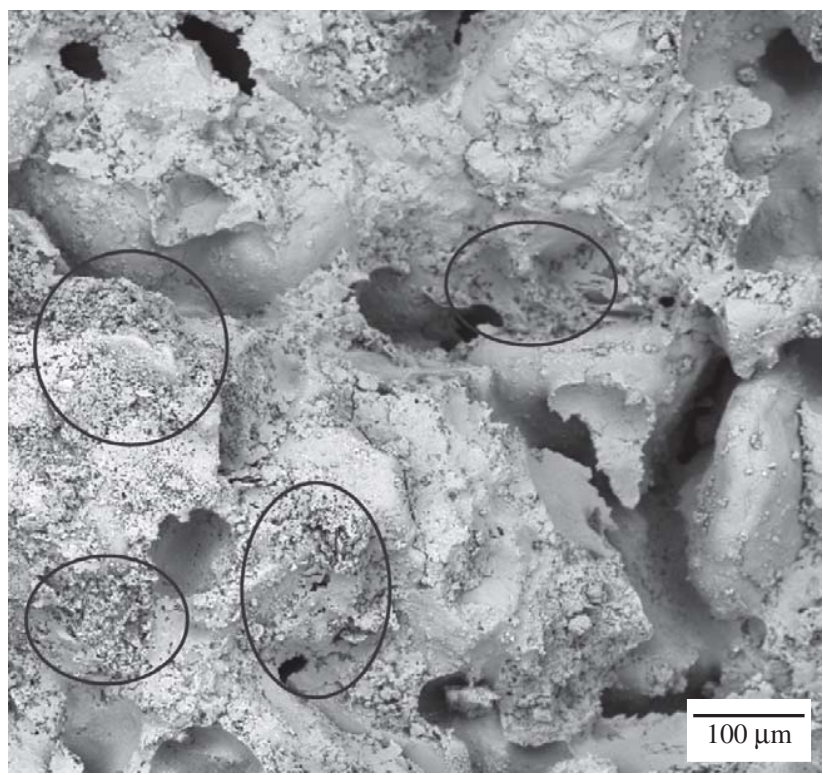

Figure 11. SEM micrograph of disintegrated residue in the mortar containing bottom ash with 0.59 to $1 \mathrm{~mm}$ grain sizes.

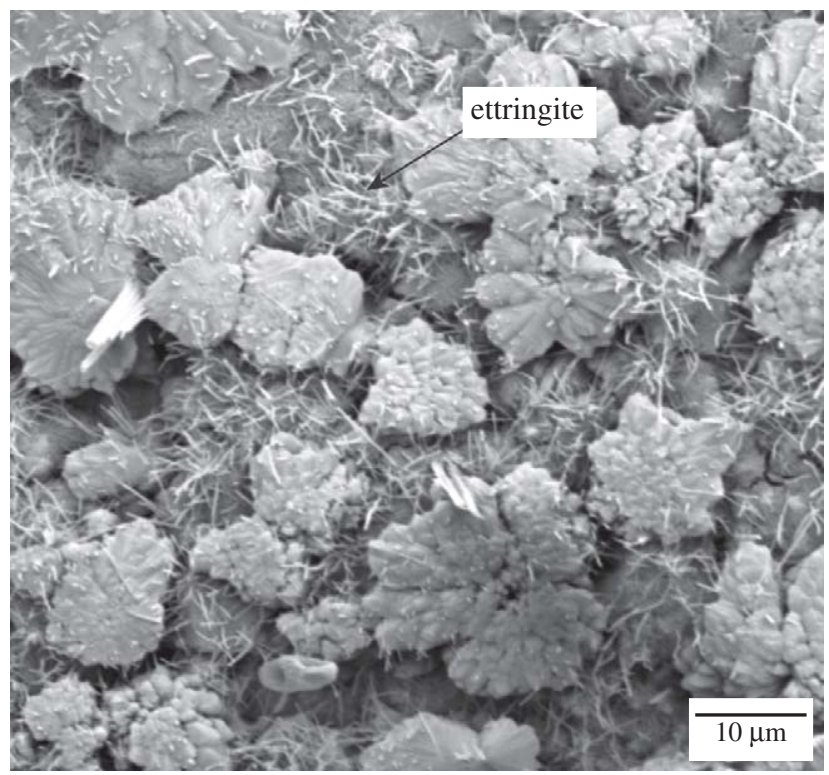

Figure 12. Micrograph of the mortar containing residue with grain sizes of 1 to $2 \mathrm{~mm}$, showing ettringite crystals.

compared with the sample containing the same residue grain size but a higher concentration of bottom ash. Figures 21 and 22 reveal the growth of ettringite crystals and lower porosity.

The samples containing 15 and $20 \%$ of residue, Figs. 23, 24,25 and 26, showed a more homogeneous distribution of the residue than the samples with grain size over $0.15 \mathrm{~mm}$. 


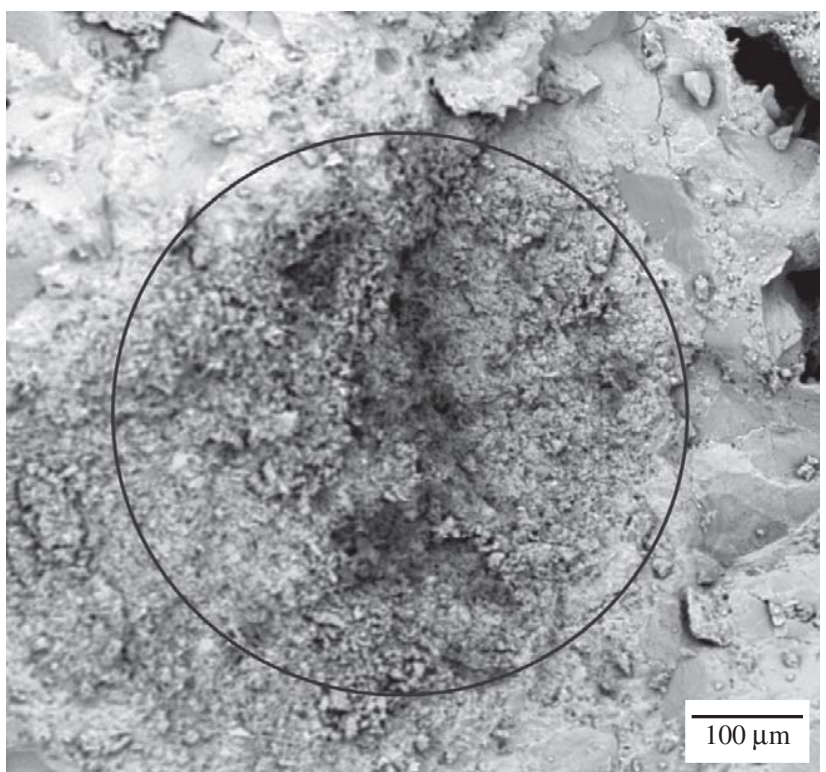

Figure 13. Micrograph of the mortar containing residue with grain sizes of 0.59 to $1 \mathrm{~mm}$, revealing bottom ash agglomerated in localized sites.

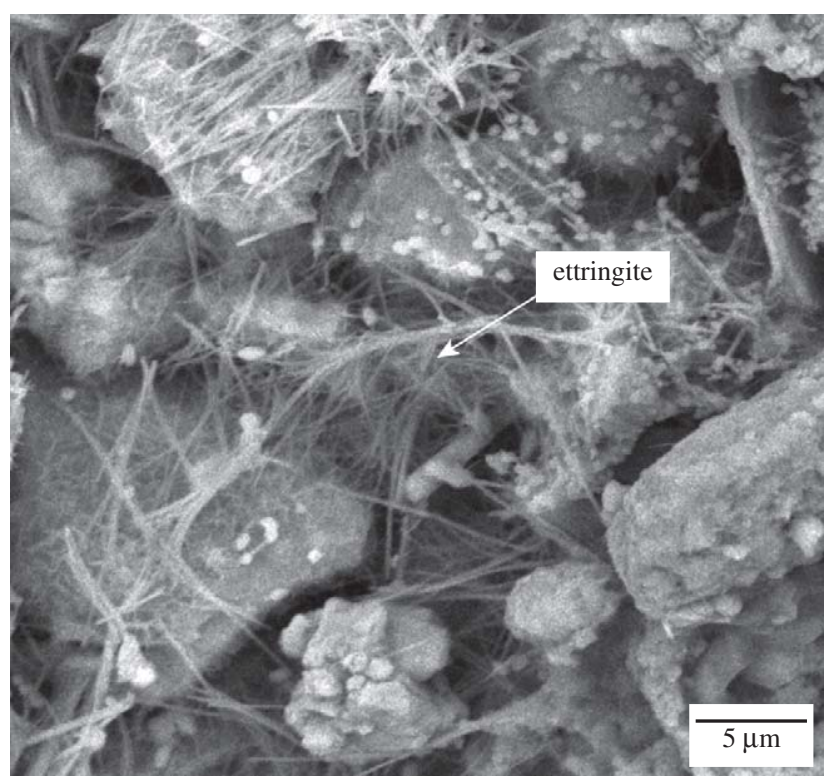

Figure 14. Micrograph of the mortar containing residue with grain sizes of 0.59 to $1 \mathrm{~mm}$, showing ettringite crystals in the regions close to the bottom ash agglomerates.

These samples also showed a slight increase in porosity and greater inhibition of ettringite crystal growth than in the samples containing lower concentrations of residue.

\subsection{Leaching tests}

Leaching tests were carried out following the Brazilian

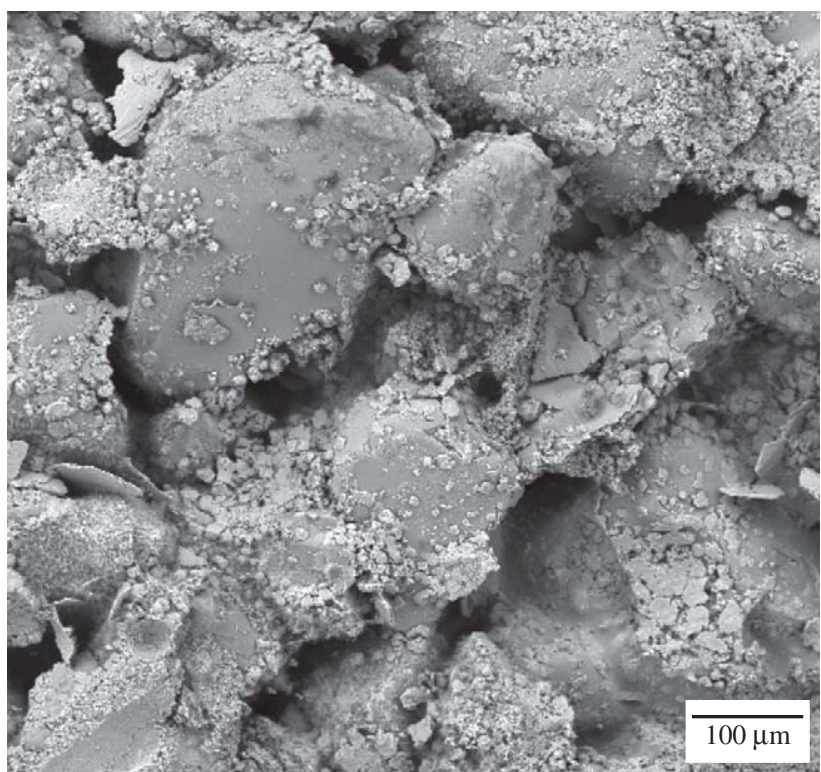

Figure 15. Micrograph of the mortar containing residue with grain sizes of 0.30 to $0.59 \mathrm{~mm}$, showing a more homogeneous distribution of the bottom ash.

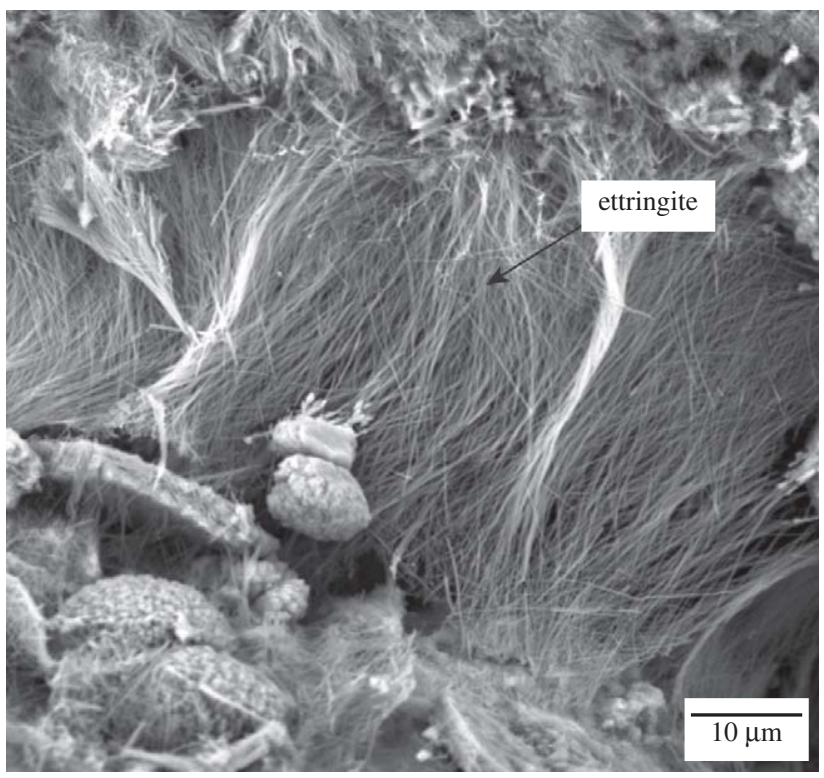

Figure 16. Micrograph of the mortar-containing residue with grain sizes of 0.30 to $0.59 \mathrm{~mm}$, highlighting the ettringite crystals.

NBR 10004 code. Complementary solubilization tests were not performed because our purpose was not to classify the materials but to ascertain, in the first phase, if certain chemical elements of the residue can be retained in the cement paste. The chemical elements chosen for leaching tests were those that represent the highest risk to fauna and flora. These 


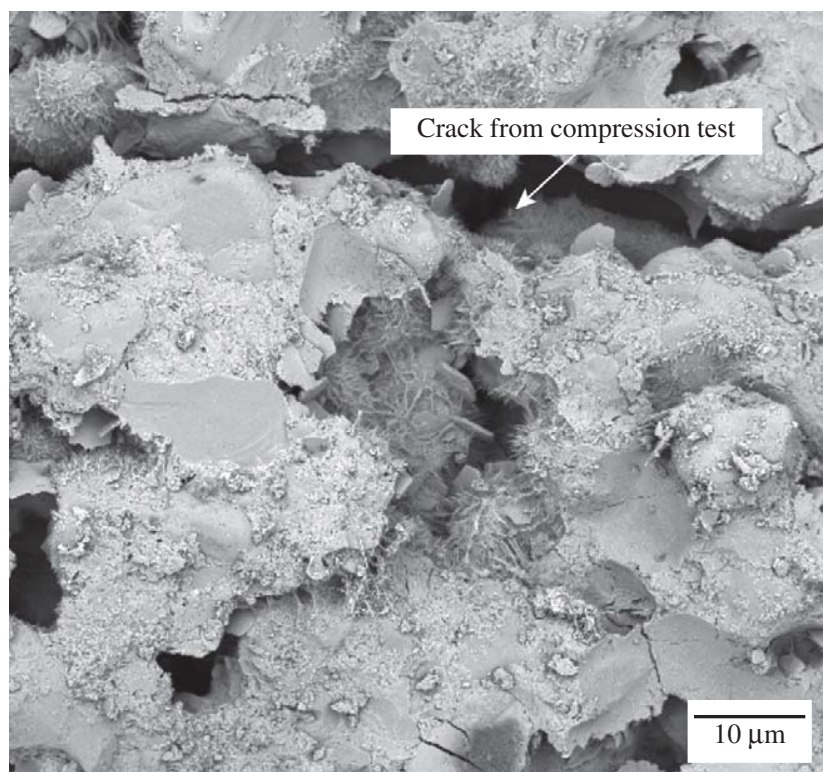

Figure 17. Micrograph of the mortar-containing residue with grain sizes of 0.15 to $0.30 \mathrm{~mm}$ showing the cement gel.

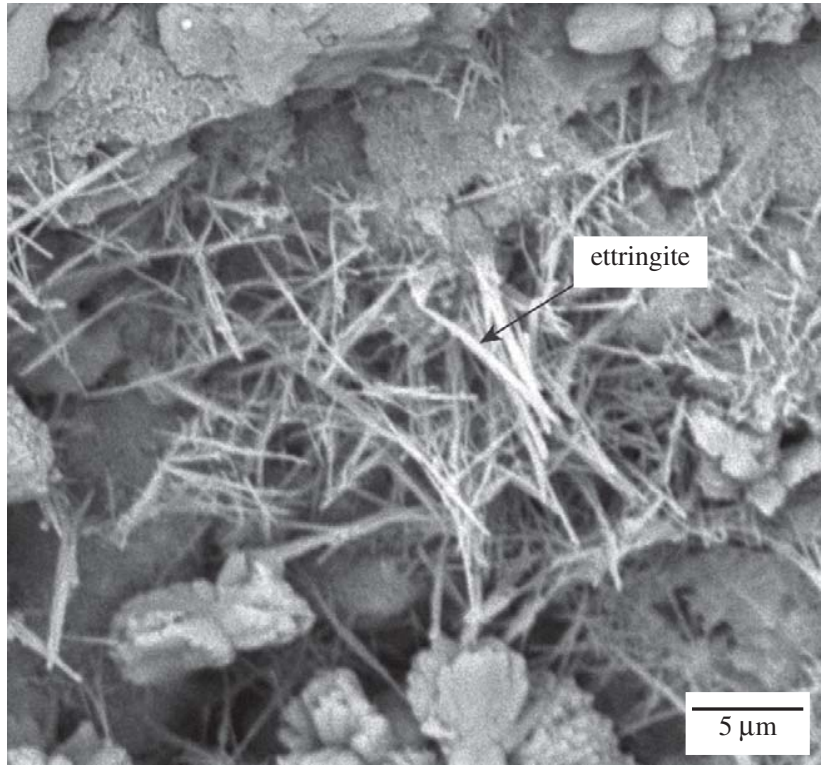

Figure 18. Micrograph of the mortar-containing residue with grain sizes of 0.15 to $0.30 \mathrm{~mm}$, highlighting the irregular growth of the ettringite crystals.

are, in general, chemical elements responsible for classifying the residue as Class II waste.

Table 6 shows the chemical analyses of the leached material. It was found that, in every sample, the chemical elements analyzed all displayed concentrations below the maximum limits established by the NBR 10004 code. An analy-

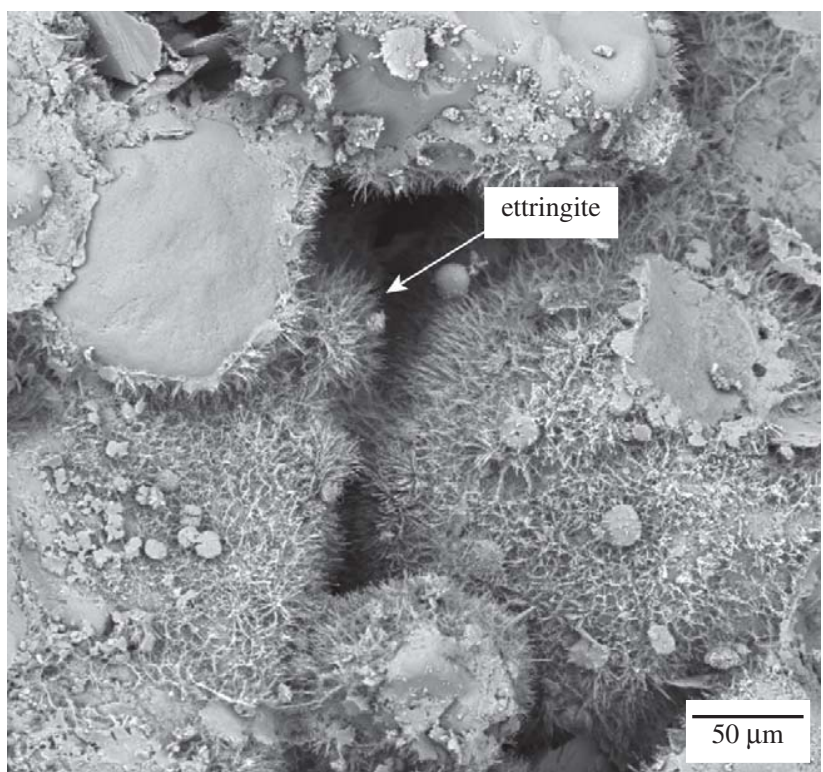

Figure 19. Micrograph of the mortar containing residue with a grain size of less than $0.15 \mathrm{~mm}$, highlighting the ettringite crystals.

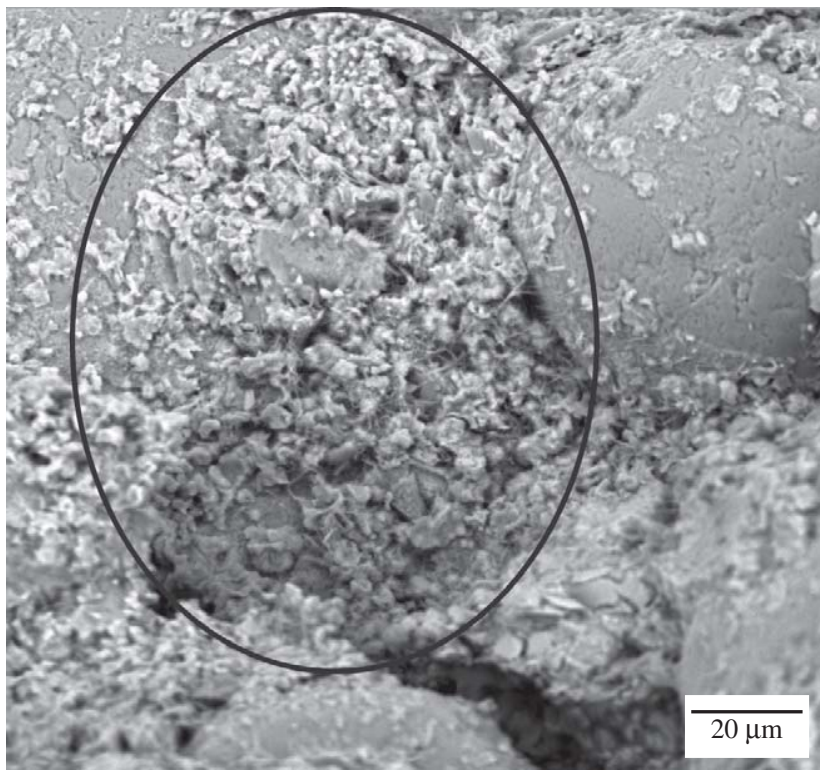

Figure 20. Micrograph of the mortar-containing residue with a grain size of less than $0.15 \mathrm{~mm}$, revealing the presence of bottom ash.

sis of the results indicated that the chemical elements from the leached extracts of mortar without residue and with $20 \%$ of residue showed similar concentrations. A rough estimate indicates that, if the $20 \%$ of residue incorporated into the mortar in place of cement displayed leaching proportional to the samples containing $100 \%$ of bottom ash, the values 


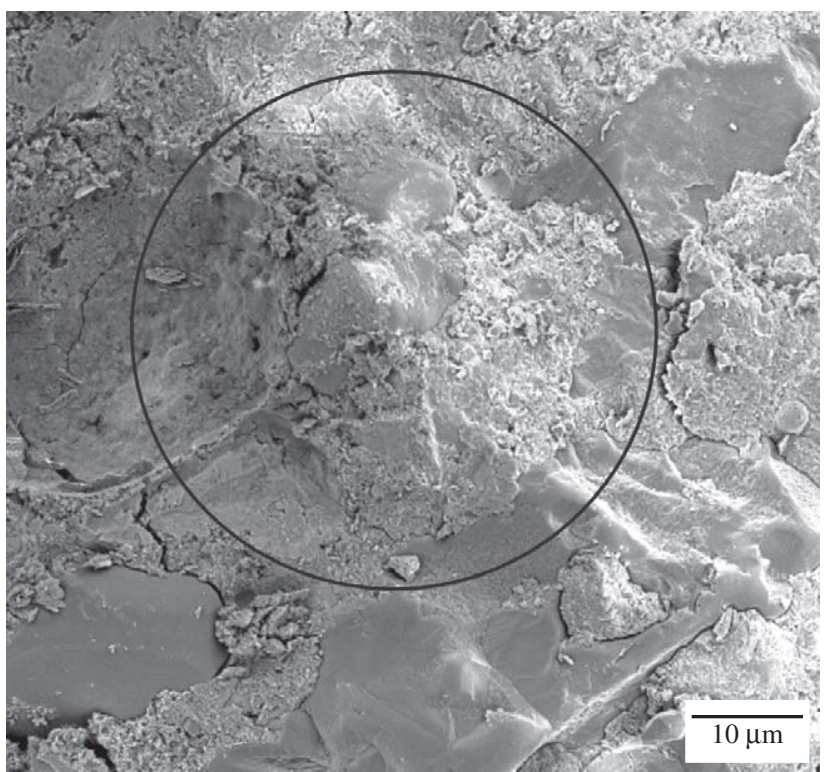

Figure 21. Micrograph of the mortar containing 5\% of residue with grain size under $0.15 \mathrm{~mm}$, highlighting good gel/aggregate interaction.

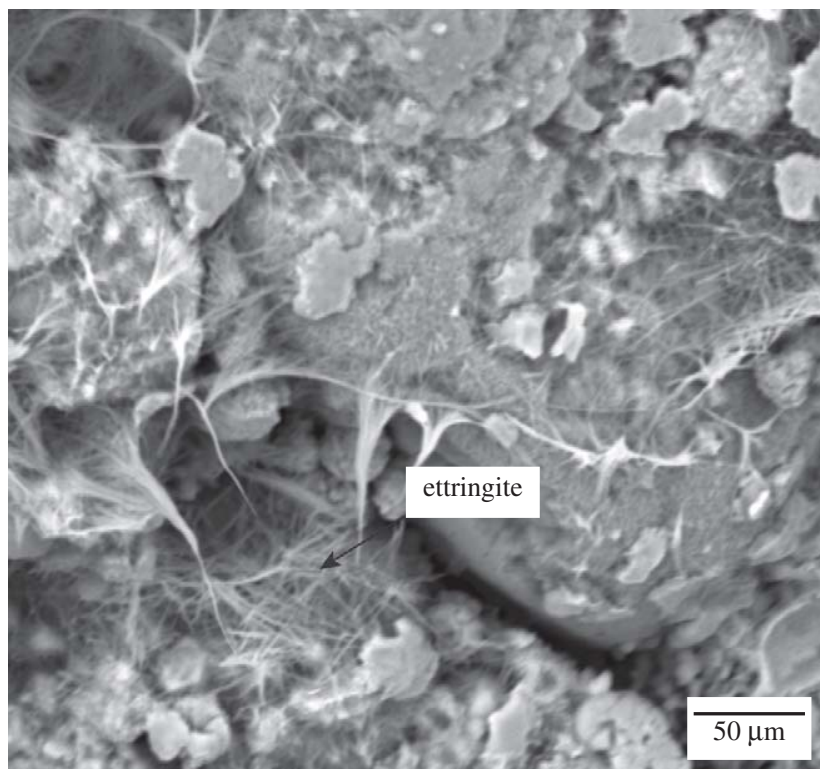

Figure 22. Micrograph of the mortar containing 5\% of residue with grain size under $0.15 \mathrm{~mm}$, showing the ettringite crystals.

found for the mortar containing $20 \%$ of residue should generally be greater than those of the mortar without residue. This led to the conclusion that the majority of the chemical elements analyzed were practically stabilized and/or encapsulated within the cement paste. However, to reach a more conclusive result, further analyses are required, especially

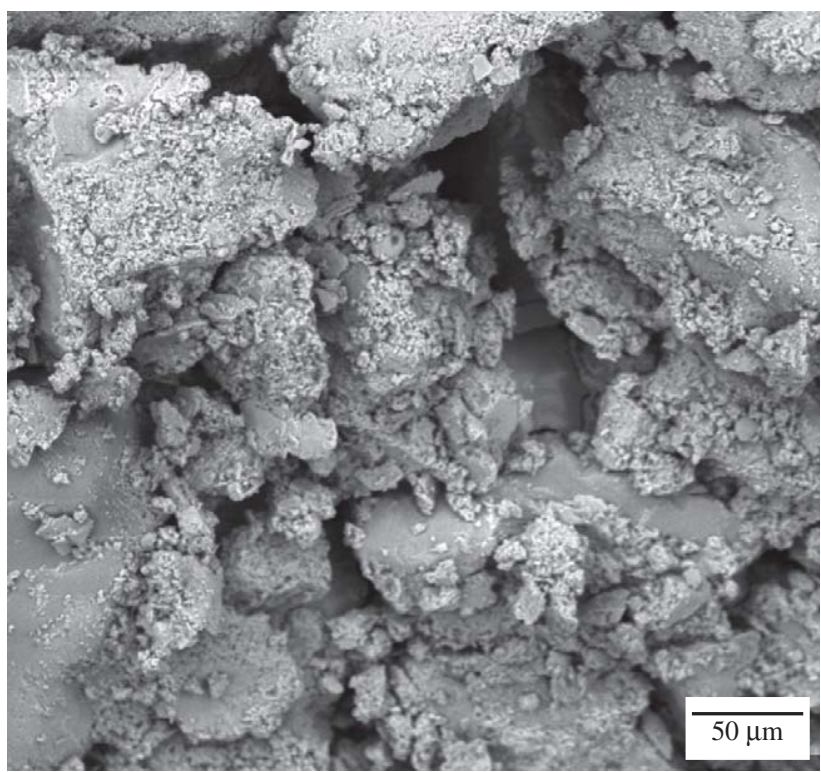

Figure 23. Micrograph of the mortar containing $15 \%$ of residue with grain size under $0.15 \mathrm{~mm}$, illustrating the distribution of the residue.

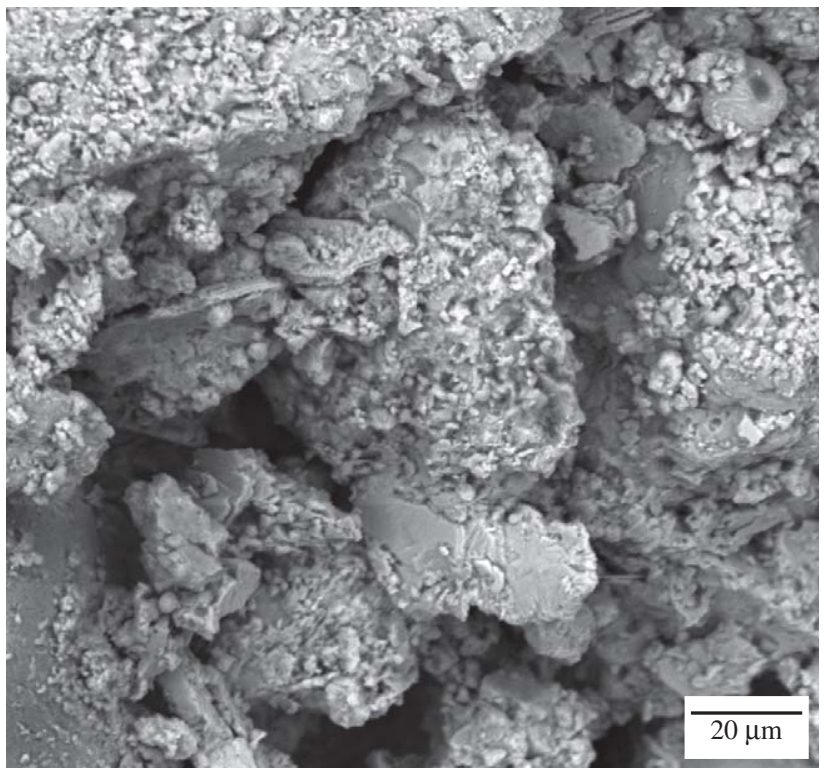

Figure 24. Micrograph of the mortar containing $15 \%$ of residue with grain size under $0.15 \mathrm{~mm}$ (greater magnification).

solubilization tests, including all the chemical elements established by international standards.

\section{Discussion of the Results}

The raw materials used in this investigation possess some specific known characteristics, which were validated before 


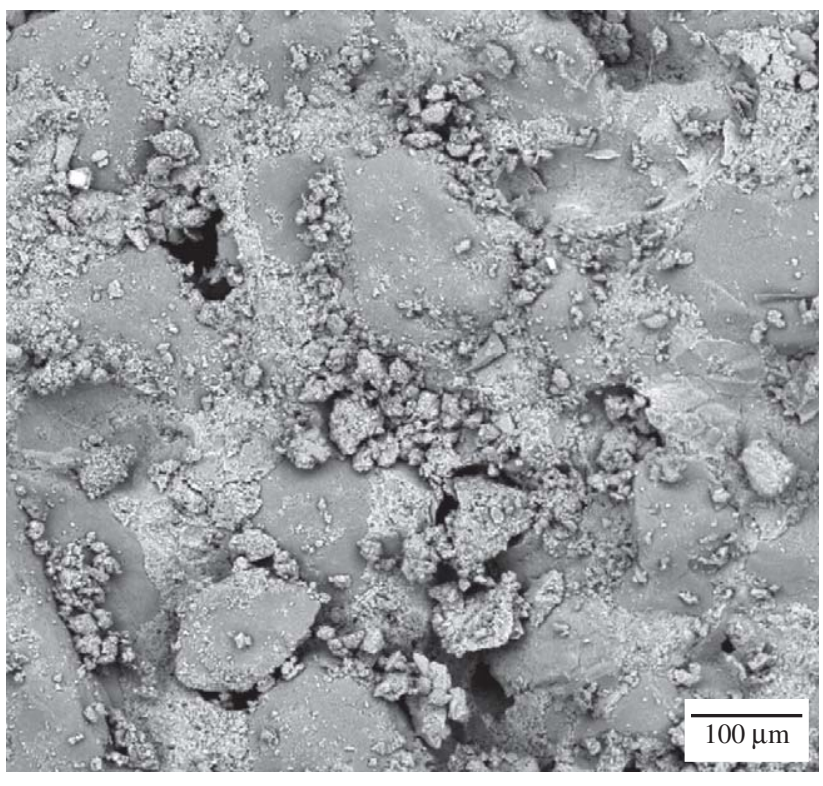

Figure 25. Micrograph of the mortar containing 20\% of residue with grain size under $0.15 \mathrm{~mm}$, showing a greater concentration of bottom ash.

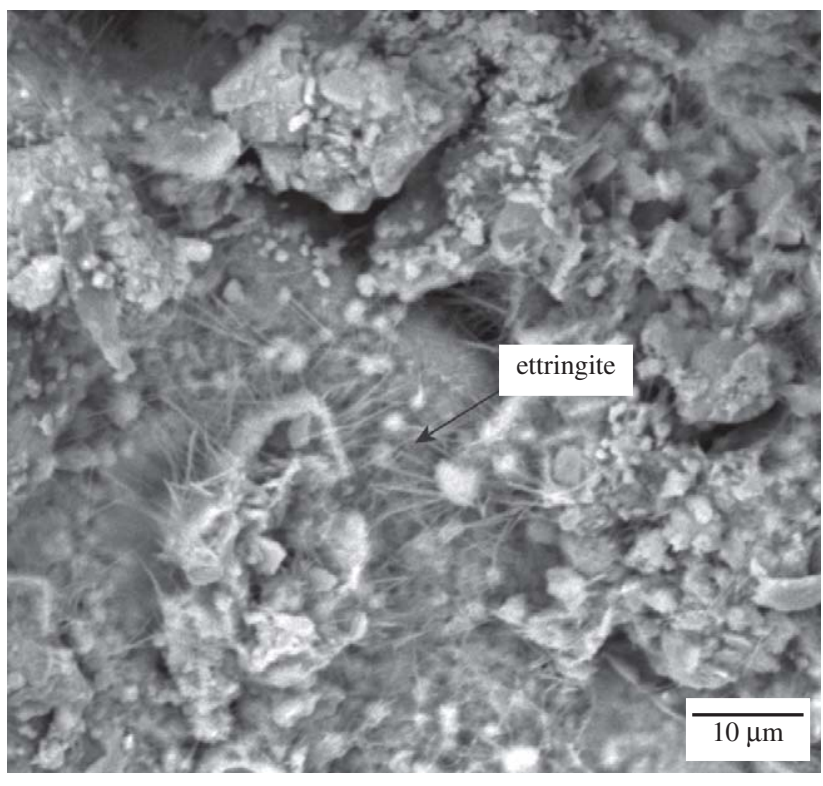

Figure 26. Micrograph of the mortar containing 20\% of residue with grain size under $0.15 \mathrm{~mm}$, depicting the ettringite crystals.

Table 6. Chemical analysis of the leached extracts.

\begin{tabular}{ccccc}
\hline Element & $\begin{array}{c}\text { Bottom Ash } \\
(\mathrm{mg} / \mathrm{l})\end{array}$ & $\begin{array}{c}\text { Mortar with 20\% } \\
\text { of bottom ash }(\mathrm{mg} / \mathrm{l})\end{array}$ & $\begin{array}{c}\text { Mortar without } \\
\text { residue }(\mathrm{mg} / \mathrm{l})\end{array}$ & $\begin{array}{c}\text { Maximum Limit } \\
\text { NBR 10004 (mg/l) }\end{array}$ \\
\hline Chromium & Not detected & 0.0874 & 0.162 & 5.0 \\
Arseno group & 0.00803 & 0.00082 & 0.00062 & 5.0 \\
Lead & 0.00120 & 0.00083 & 0.00072 & 5.0 \\
Selenium & Not detected & Not detected & 0.00145 & 1.0 \\
Silver & 0.00074 & 0.000384 & 0.00028 & 5.0 \\
Cadmium & 0.000198 & 0.000366 & 0.00043 & 0.5 \\
Barium & 0.392 & 0.634 & 0.660 & 100.0 \\
Mercury & 0.00158 & 0.00074 & 0.00040 & 0.1 \\
Chlorides & 0.0000178 & 0.00000890 & 0.00000890 & - \\
Fluorides & 0.00000026 & 0.00000165 & 0.00000158 & 150.0 \\
\hline
\end{tabular}

the mortars were prepared. The sand was found to be of good quality, showing a low concentration of impurities and grains with an irregular geometry. This characteristic of the sand grains may reduce the workability of the mortar but, on the other hand, enables the cement paste to adhere more easily on the surface of the sand grains. The EDS analysis also revealed that the two main oxides of bottom ash, i.e., calcium oxide and silicon oxide, are also the two main components of cement, indicating that bottom ash has a certain chemical affinity with cement. This chemical similarity is clearly visible through a comparison of the chemical analyses of the residue and the cement (Tables 1 and 2). Magne- sium oxide is another chemical compound present in the two materials; however, the bottom ash showed a high concentration of "inert ash" (approximately 47\%) and a small concentration of sulfur. The Brazilian NBR 10004 code classifies bottom ash as non-inert, which means that at least some of the components of bottom ash may react and/or hydrate during hydration of the cement paste. Although this could reinforce the idea of using this residue as a partial substitute for cement, it should be noted that a large amount of supposedly inert bottom ash present in the residue may inhibit or counterbalance the possible positive effect of certain elements of the residue, and may even lead to an overall negative ef- 
fect on the hydration process of the binder. Therefore, it is impossible to state unequivocally that the reduction in mechanical strength of the samples containing residue was also due to the reduction in the amount of cement, since part of it was replaced by residue. Should such a statement be made, it would be based on the assumption that the residue does not positively affect the hydration process of the cement paste. On the other hand, it is possible to affirm that the mechanical strength depends on the distribution of the residue in the mortar. It was observed that the residue grains are visible as defects in the cement paste because they disintegrate easily under mechanical forces. The larger the grains the greater the defects and, hence, the lower the mechanical strength. This effect of the grains is illustrated in the graph showing the mechanical strength in Fig. 1. In contrast, Fig. 2 reveals greater mechanical strength even at higher concentrations of residue, but with smaller grain sizes than those of Fig. 1.

The metallographic analysis carried out by SEM revealed that, in the sites where the waste accumulated, the "inert ash" contained in the waste inhibited the formation and growth of ettringite crystals. The residue also contains sulfur, which may react with calcium to form ettringite crystals, but these chemical elements encounter unfavorable conditions when in contact with inert ash. The effect of inert ash on mechanical strength has already been demonstrated in earlier studies ${ }^{5}$, in which two commercial Portland cements were used - CPII-Z-32 and CPI-S-32. The former, CPII-Z-32, containing a large amount of inert ash, showed low mechanical strength in the order of $5 \mathrm{MPa}$ after 28 days of curing in a saturated medium. The mortar obtained with the same formulation, but with the CPI-S-32 cement, displayed a much higher mechanical strength of around $21 \mathrm{MPa}$ after 28 days of curing in a humid saturated medium. The latter mortar showed mechanical strength comparable to that of the mortar without residue produced in the present study (22 MPa). However, it must be kept in mind that the grain size of the sand used in the present study was smaller than that utilized by the above-cited authors and that this may have influenced the values of mechanical strength of the mortars/concretes. Certain cements are commercialized on a large scale, as in the case of the CPII-Z-32 cement. The "inert ash" found in this cement originates from incinerators or from thermoelectric plants, and is often used to reduce the cost of cement ${ }^{6,7}$. Since the raw (unprocessed) residue exists in the form of agglomerates of a few centimeters in size, we suggest to grind it together with the clay or limestone used in the production of cement in order to avoid processing it separately and then add it to the mortar, as done here. For the pulp and paper industry, it would be a great advantage, from the standpoint of cost and environmental responsibility for the residue, to have its waste used in the production of cement. The pulp and paper industry could supply the residue to the cement industry, totally cost- free including transportation, since that would be cheaper than depositing it in an industrial landfill, as is the current practice. Moreover, when a residue is transformed into a raw material, the company generating the waste is exempt of environmental responsibility, provided the residue loses its characteristics. Coprocessing systems such as those employed by cement manufacturers cause the residue to lose its characteristics, thus exempting the original generator of the waste (after the process is completed) from responsibility for the processed product. Of course, the use of residue as a raw material depends on its behavior in relation to the environment. This evaluation is quite a complex one because, on the one hand, the current code is limited to naming and classifying industrial by-products as Class I, II or III residues, without evaluating the purposes and conditions of use of materials that could be produced with residues. On the other hand, there are many materials and raw materials that, if assayed by leaching and solubilization tests, would be classified as residues. That is the case of some types of cement currently manufactured and commercialized. Therefore, it is difficult in this study to reach a conclusion about the commercial use of bottom ash based on leaching and solubilization tests. All that can be said is that the concentrations of chemical elements analyzed in the mortar with and without residue were very similar and lower than the maximum limit established by the Brazilian NBR 10004 code, and that is highly probable that at least certain chemical elements of the residue remain partially encapsulated, chemically or mechanically, within the cement paste. It is also worth pointing out that some European countries take a different approach to the question of wastes. In France, today, a federal law requires that companies reduce the quantity of wastes destined for industrial landfills. Certain industrial wastes can no longer be deposited in such landfills and must be used as raw materials, mainly in public works, or for the generation of energy. Nowadays, the use of wastes in materials depends largely on cost. However, for sustainable development, other parameters will have to be taken into consideration that undergo the creation of federal laws and a new concept and policy of utilization of materials.

\section{Conclusions}

The study demonstrated that it is possible to use the residue deriving from burned biomass (bottom ash) from Klabin's pulp and paper plant in the manufacture of mortars. An investigation was made on the influence of grain size and the concentration of residue on the mechanical, microstructural and environmental behavior of the mortar.

The residue was processed and incorporated, in various grain sizes and concentrations, into the mortar as a mineral addition to the cement. The results of the mechanical compression tests revealed that the mortar strength depends on grain size, concentration and distribution of the residue in 
the microstructure of the mortar. The samples prepared with $10 \%$ of residue of different grain sizes showed a marked drop in mechanical resistance as the grain size of the residue increased. For residue grain sizes of less than $0.15 \mathrm{~mm}$, the mechanical resistance was $20 \mathrm{MPa}$, very close to the mechanical strength of mortar without residue (22 $\mathrm{MPa})$. With a grain size of 0.30 to $0.59 \mathrm{~mm}$, the mechanical strength dropped to $13 \mathrm{MPa}$, and then to $9 \mathrm{MPa}$ in the mortar containing residue grain sizes of 1 to $2 \mathrm{~mm}$.

In the test specimens prepared with various concentrations of residue having grain sizes below $0.15 \mathrm{~mm}$, the decrease in mechanical strength was small and linear, i.e., around $0.16 \mathrm{MPa}$ for every $1 \%$ of residue added to the mortar. Therefore, for $20 \%$ of residue, the decrease in average rupture stress was 3.21 MPa, i.e., from $22 \mathrm{MPa}$ for the mortar without residue to $18.8 \mathrm{MPa}$ for the mortar containing $20 \%$ of residue. These findings indicate that it is more advantageous to use $20 \%$ of residue with a grain size of less than $0.15 \mathrm{~mm}$ than any of the other grain sizes tested with $10 \%$ of residue in the mortar.

The microstructural analysis indicated that the mechanical resistance of the samples was dependent on the concentration of inert ash in the residue and on the distribution of the residue in the mortar. This finding is clearly visible in the samples containing larger residue grain sizes. The residue's grains appear in the structure of the mortar as points of concentration of inert ash owing to the large quantity of this material in the residue. These points, or sites, of inert ash concentrations embrittle the mortar by inhibiting the formation and growth of ettringite crystals and by forming points of discontinuity in the cement paste (defects). The more homogeneous the residue's distribution and the smaller its grain size, the lower the amount and size of the discontinuities in the cement paste (the fewer the number and size of defects) and also the less the interference of the residue in the process of hydration and crystallization of the compounds in the cement paste. The reduction in mechanical strength may also have been partially due to the decrease in the amount of cement in the formulations containing residue.

With regard to the leaching tests, it was found that the concentration of the chemical elements analyzed in the leached extracts of the mortar containing $20 \%$ of residue and in the mortar without residue was very similar, and that the mortar with residue generally presented slightly higher values. All the substances analyzed displayed concentrations below those of the maximum limit established by the Brazilian NBR 10004 code, and it is likely that many of the chemical elements possibly harmful to humans and to the environment become partially chemically stabilized (bonded) or solidified within the cement paste.

Lastly, it would be interesting to investigate the possibility of incorporating the residue in the cement manufacture. It would, in that case, be processed together with the clay or limestone used in the manufacture of cement. It would be a raw material supplied at no cost by the residue generating plant and could reduce the price of commercial cement, as in the case of the use of ash deriving from incinerators or thermoelectric power plants. Therefore, the residue could be added to mortars or concretes indirectly through cement.

\section{References}

1. Masuero, A.B.; Dal Molin, D.C.C.; Vilela, A.F. Anais do $13^{\circ}$ CBECIMAT, CDROM, p. 4769, 1988.

2. Moura, W.A.; Dal Molin, D.C.C.; Vilela, A.F. Anais do $13^{\circ}$ CBECIMAT, CDROM, p. 3403, 1988.

3. Teles, A.R.; Camargo, N.H.A. Elaboração e Caracterização de Blocos para Construção Civil a Partir de Resíduos sólidos Industriais, Relatório de Iniciação Científica, CNPq, p. 51, 1999.

4. Watanabe, A.P.; Nunes, J.J.; Rebello, L.; Moreno, M.A.; Mendes, J.M.M.; Buchler, P.M. Anais do $38^{\circ}$ Congresso Brasileiro de Cerâmica e $2^{\circ}$ Encontro de Mineradores e Consumidores, v. 2, p. 546, 1994.

5. Gemelli, E.; Camargo, N.H.A.; Brescansin, J. Materials Research, v. 4, n. 4, p. 297, 2001.

6. Bruder-Hubscher, V.; Lagarde, F.; Maurice, L. Déchet: Sciences \& Techniques, n. 18, p. 3, 2000.

7. Bruder-Hubscher, V.; Lagarde, F.; Maurice, L. Déchet: Sciences \& Techniques, n. 18, p. 8, 2000.

8. Stegemann, J.A.; Schneider, J.; Baetz, B.W.; Murphy, K.L. Waste Management and Research, v. 13, p. 149, 1995.

9. Baker, D.E.; Chesnin, L. Advanced Agronomy, v. 27, p. 305, 1975.

10. Alba, N.; Gassos, S.; Lacorte, T.; Baldasano, J.M. Air and Waste Management Association, v. 47, p. 1170, 1997. 